\title{
Écija en las páginas web de Turismo Andaluz y de la Diputación Provincial de Sevilla
}

Podemos encontrar también información sobre Écija en dos direcciones institucionales más amplias: Web oficial de Turismo Andaluz (http://www.andalucia.org) y Web de la Diputación Provincial de Sevilla (http://www.dipusevilla.es).

La Web de la Diputación de Sevilla dispone de una apartado dedicado a Municipios dónde se puede seleccionar cualquiera de los que forman parte de la provincia. Una vez elegido Écija accedemos a una página (http://www.dipusevilla.es/ayun/ecija/general.htm) encabezada por diez iconos que dan paso a contenidos sectoriales sobre esta población sevillana, éstos en concreto son: Heráldica, Historia, Monumentos, Gastronomía, Economía, Fiestas, Turismo, Población, Planos y Presupuestos. Hay que indicar que este esquema se repite para los demás municipios de la provincia.

En esta página nos encontramos a su vez con datos geográficos generales sobre la localidad (superficie, habitantes, etc.) y un plano de situación de la misma en la provincia de Sevilla. También aparece un enlace a la composición política actual del Ayuntamiento.

En cuanto a los contenidos sectoriales antes mencionados, nos encontramos con una información desigual, que resumimos a continuación. En primer lugar el icono de Heráldica nos lleva al escudo de la ciudad acompañado de su descripción, en Historia accedemos a breves reseñas de las épocas que se consideran de más relevancia en su historia local. Monumentos, quizás el apartado con más contenido, incluye información sobre 38 edificios de la ciudad, tanto religiosos como civiles. La información sobre cada uno de ellos no sigue una estructura clara y es muy variable, a veces nos encontramos con textos bastante amplios y otras con tan sólo una frase. Normalmente no se reseñan los datos de protección de este patrimonio arquitectónico o incluso aparecen datos obsoletos (por ej. nos encontramos con que se habla en algún caso de la categoría de uno de los edificios como "Monumento

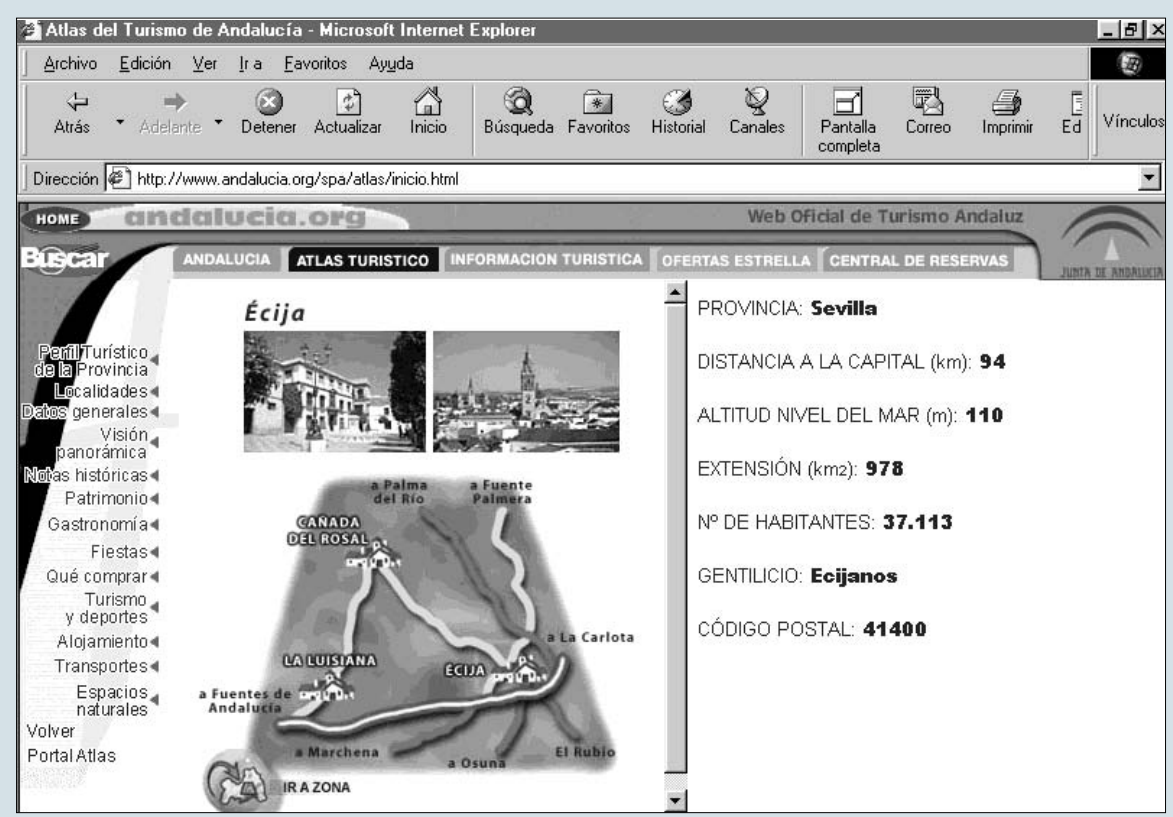

\section{FICHA DE LA WEB}

URL PRINCIPAL

URL SECUNDARIA

INFORMACIÓN DISPONIBLE

CALIDAD GRÁFICA

DISEÑO WEB

FACILIDAD DE NAVEGACIÓN

VELOCIDAD DE CARGA

ACTUALIZACIÓN

CALIDAD GLOBAL http://www.andalucia.org

http://www.andalucia.org/spa/atlas/sevilla/municipios/ecija

Media

Aceptable

Aceptable

Aceptable

Aceptable

No presenta fecha

Aceptable
Nacional") En algunas ocasiones se dispone de imágenes asociadas, de carga bastante lenta.

En el apartado de Gastronomía, se nos comentan los platos ecijanos más típicos. Hay que reseñar que tanto en este apartado como en los de Fiestas, Turismo y Población los enlaces no son directos, sino que nos llevan a los primeros apartados ya comentados, y hay que buscar el enlace con la página siguiente. Economía, hace alusión a las industrias más importantes de la localidad y se presentan las páginas del BOP referentes a los presupuestos generales de 1997 y 1998. Sin embargo, a los presupuestos más recien- tes se accede desde el apartado de Presupuestos. En Fiestas, disponemos de una agenda cronológica con los eventos más relevantes del municipio. Turismo, cita por un lado, diversos monumentos pero de forma no homogénea y se echan de menos datos relevantes como los horarios de visita. Por otro lado, consta de una sección de Hostelería clasificada por categorías, y de otra de direcciones de interés (policía, transportes, etc.). En este apartado se encuentran conexiones a otras dos Web: Hospital de San Sebastián (http://www.hospssebastian.es) que no funciona bien actualmente y Ayuntamiento de Écija (http://www.ecija.org), de la que se habla específicamente en este Boletín. 
Población, contiene tablas de los habitantes del municipio desde 1842 a 1996. Planos, ofrece un plano del núcleo (actualmente no disponible) y una fotografía aérea. El último apartado dedicado a Presupuestos nos permite acceder a los presupuestos del 2001 y contiene enlaces a presupuestos anteriores.

En resumen, nos encontramos con unos contenidos variados y con grandes desniveles de información. La presentación de dicha información es bastante estática, ya que ofrece poca navegación e interactividad y el diseño de las páginas es poco novedoso. No hay que olvidar que las páginas que se comentan forman parte de una Web mucho más amplia que entre otros proyectos, aborda el suministrar información sobre todos los municipios de la provincia de Sevilla. Se entiende, por tanto, la dificultad del mantenimiento sectorial. Sería muy interesante profundizar y actualizar esta amplia estructura informativa.

Por otra parte, dentro de la Web Oficial de Turismo Andaluz (http://www.andalucia.org) encontramos también información de la localidad de Écija. Esta dirección nos presenta en su apartado Atlas Turístico la posibilidad de acceder a información sobre los diversos municipios andaluces organizados por provincias, ya sea a través de un mapa interactivo o de la selección sobre el listado de localidades. (http://www.andalucia.org/spa/atlas/inicio.html.) Una vez seleccionado el municipio de Écija entramos a una página con una serie de opciones de navegación alineadas a la izquierda, además de disponer de datos geográficos muy genéricos, de un mapa de situación en el entorno de la provincia y de dos imágenes de la localidad.

En la opción de Visión panorámica, se nos da una breve reseña de la localidad. Notas Históricas es un resumen muy somero de la historia local organizado por grandes períodos y que finaliza con la enumeración de personajes destacados. Hay un apartado dedicado a Patrimonio en el que se recogen 35 edificios con una breve descripción, a veces sólo se indica la cronología. Se distingue un subapartado de Urbanismo, cuyo contenido no posee un diferencia conceptual clara con el resto de la información. También se recoge un epígrafe dedicado a Museos, que en este caso sólo indica el museo parroquial sin añadir ningún dato sobre el mismo. Tampoco aquí se hace hincapié en los datos de protección de este patrimonio y nos encontramos como en el caso de la Web de la Diputación de Sevilla con datos poco actualizados (Es curioso que también se hace referencia a la protección como Monumento Nacional de un edificio). Gastronomía, hace alusión a los platos más típicos, con casi la misma información que en las páginas Web comentadas anteriormente. En Fiestas, se citan simplemente las más relevantes. En Qué comprar, Alojamiento y Transportes, se accede a búsquedas por denominación o por diferentes tipologías que nos dan como resultado listados de directorio. Turismo y deportes, nos suministra una referencia de interés en la localidad. Y por último Espacios Naturales nos lleva a un mapa de los espacios naturales de la provincia en general.

Tenemos también este caso un estructura variada de contenidos, en muchos aspectos coincidentes con las páginas de la Diputación Provincial de Sevilla comentadas anteriormente. Las divergencias vienen dadas por el enfoque lógico de cada organismo responsable. Hay que resaltar que el diseño es más ameno que en el caso anterior y también es mejor la navegación, aunque los contenidos son menores. Por tanto, hay que volver a insistir en la necesidad de profundizar y actualizar estos contenidos.

Ángela Blanco Muriel Centro de Documentación del IAPH 